\title{
Core Temperature Responses and Match Running Performance During Intermittent- SPRINT EXERCISE CoMPETITION IN WARM Conditions
}

\author{
Rob Duffield, ${ }^{1}$ Aaron J. Coutrs, ${ }^{2}$ and John Quinn ${ }^{3}$ \\ ${ }^{1}$ School of Human Movement Studies, Charles Sturt University, Bathurst, Australia; ${ }^{2}$ School of Leisure, Sport and Tourism, \\ University of Technology, Sydney, Australia; and ${ }^{3}$ Essendon Football Club, Essendon, Australia
}

\begin{abstract}
Duffield, R, Coutts, AJ, and Quinn, J. Core temperature responses and match running performance during intermittent-sprint exercise competition in warm conditions. $J$ Strength Cond Res 23(4): 1238-1244, 2009-This study investigated the thermoregulatory responses and match running performance of elite team sport competitors (Australian Rules football) during preseason games in a warm environment. During 2 games in dry bulb temperatures above $29^{\circ} \mathrm{C}\left(>27^{\circ} \mathrm{C}\right.$ wet bulb globe temperature), 10 players were monitored for core temperature $\left(T_{\text {core }}\right)$ via a telemetric capsule, in-game motion patterns, blood lactate $\left(\left[\mathrm{La}^{-}\right]\right)$, body mass changes, urine specific gravity, and pre- and postgame vertical jump performance. The results showed that peak $\mathrm{T}_{\text {core }}$ was achieved during the final quarter at $39.3 \pm 0.7^{\circ} \mathrm{C}$ and that several players reached values near $40.0^{\circ} \mathrm{C}$. Further, the largest proportion of the total rise in $\mathrm{T}_{\text {core }}$ $\left(2.1 \pm 0.7^{\circ} \mathrm{C}\right)$ occurred during the first quarter of the match, with only small increases during the remainder of the game. The game distance covered was $9.4 \pm 1.5 \mathrm{~km}$, of which $2.7 \pm 0.9$ $\mathrm{km}$ was at high-intensity speeds $\left(>14.4 \mathrm{~km} \cdot \mathrm{h}^{-1}\right)$. The rise in $\mathrm{T}_{\text {core }}$ was correlated with first-quarter high-intensity running velocity $(r=0.72)$ and moderate-intensity velocity $(r=0.68)$, second-quarter $\mathrm{T}_{\text {core }}$ and low-intensity activity velocity ( $r=$ -0.90 ), second-quarter $T_{\text {core }}$ and moderate-intensity velocity $(r=0.88)$, fourth-quarter rise in $T_{\text {core }}$ and very-high-intensity running distance $(r=0.70)$, and fourth-quarter $\mathrm{T}_{\text {core }}$ and moderate-intensity velocity $(r=0.73)$. Additional results included mean game $\left[\mathrm{La}^{-}\right]$values of $8.7 \pm 0.1 \mathrm{mmol} \cdot \mathrm{L}^{-1}$, change in body mass of $2.1 \pm 0.8 \mathrm{~kg}$, and no change $(p>0.05)$ in pre- to postgame vertical jump. These findings indicate that the plateau in $\mathrm{T}_{\text {core }}$ may be regulated by the reduction in low-
\end{abstract}

Address correspondence to Rob Duffield, rduffield@esu.edu.au. 23(4)/1238-1244

Journal of Strength and Conditioning Research

(C) 2009 National Strength and Conditioning Association

\section{Journal of Strength and Conditioning Research"}

intensity activity and that pacing strategies may be employed during competitive team sports in the heat to ensure control of the internal heat load.

KEY WoRDs core temperature, motion analysis, team sport performance, heat

\section{INTRODUCTION}

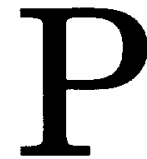

rolonged submaximal or intermittent-sprint exercise in warm environmental conditions imposes physiological strain on the thermoregulatory system that can result in a reduction in exercise performance $(4,8,17)$. While many laboratory-based studies have shown reduced intermittent-sprint performance with an increased endogenous thermal load, the mechanisms for the decline in performance remaining equivocal $(16,27)$. In regard to field-based data collection, few studies have measured core temperature $\left(\mathrm{T}_{\text {core }}\right)$ during competitive games, and, to date, there is no published literature reporting both $\mathrm{T}_{\text {core }}$ and exercise performance data during competitive match play (23). Despite the lack of field data, recent laboratory data on exercise performance in the heat highlight the importance of pacing strategies in anticipation or avoidance of increased internal heat stress (21). Pacing strategies rely on the interaction of an athlete's assessment of the external environment and afferent feedback of the internal environment to regulate exercise intensity (25). Accordingly, based on the non-specific nature of laboratory testing for team sport performance, the interaction of $T_{\text {core }}$ and exercise performance during competitive team sport exercise in warm environments has not been reported. To date, there is a lack of literature reporting the relationship between $T_{\text {core }}$ responses and exercise workload patterns during team sport competition in the heat.

Several studies have reported changes in $\mathrm{T}_{\text {core }}$ during competitive football matches $(6,14)$. However, presumably because of technical limitations, there have been no data reported for synchronous measures of both $\mathrm{T}_{\text {core }}$ and match activity patterns (performance) for team sport exercise 
involving prolonged, intermittent-sprint activity. Data collected during competitive soccer and rugby matches have shown peak $\mathrm{T}_{\text {core }}$ values in the vicinity of $38.5-39.3^{\circ} \mathrm{C}$ in cool or moderate ambient conditions $(6,14)$. Mohr et al. (15) have reported $\mathrm{T}_{\text {core }}$ values of $39.0^{\circ} \mathrm{C}$ after soccer games in cool conditions $\left(8-14^{\circ} \mathrm{C}\right)$, and although in-match running performance was not measured, repeat-sprint performance $(3 \times 30-\mathrm{m})$ decreased after the end of each half. Although this research described the internal thermal load during competitive games, it did not examine its influence on exercise performance during a match. Collectively, these data indicate that $T_{\text {core }}$ does not reach levels traditionally associated with reductions in intermittent-sprint performance when completed in cool conditions. To date, however, there are no published data describing the association of exercise performance and $T_{\text {core }}$ in competitive team sport exercise in warm environments.

Previous research has highlighted both $T_{\text {core }}$ and the rise in $T_{\text {core }}$ as potential mechanisms responsible for the reduction in exercise intensity in warm laboratory conditions $(8,20)$. As yet, this relationship has not been examined during competitive match play for team sport athletes in the heat. Therefore, the aim of this study was to examine the thermoregulatory responses and changes in the in-match running performance in field-based, intermittent-sprint exercise in professional Australian Rules football (ARF) games in warm environmental conditions.

\section{METHODS}

\section{Experimental Approach to the Problem}

To determine the relationship between thermoregulatory responses and free-paced exercise for team sports in the heat, elite Australian football players were monitored during the official preseason competition. During training sessions before the games, players were familiarized with all measures, procedures, and equipment used in the ensuing testing sessions (games). During 2 official preseason Australian Football League games in mean $\pm S D$ environmental conditions of $29.5 \pm 1.3^{\circ} \mathrm{C}, 64.9 \pm 16.7 \%$ relative humidity, and $27.6 \pm$ $2.3^{\circ} \mathrm{C}$ wet bulb globe temperature (WBGT), the players were monitored for $T_{\text {core, }}$ match running performance, blood lactate concentration $\left(\left[\mathrm{La}^{-}\right]\right)$, body mass change, voluntary recruitment of lower-body power, urine specific gravity (USG), category ratio-10 rating of perceived exertion (RPE), and rating of thermal comfort. Both games involved competitive and demanding intermittent sprints and physical body contact against similarly matched opposition teams for $4 \times 25$-minute quarters (100 minutes). In total, 14 sets of data were used in the analysis from the 10 players across the 2 games, with 4 players contributing data on 2 occasions.

\section{Subjects}

Ten male players from the same top-level professional ARF club were recruited as participants for this study. Physical characteristics included mean $\pm S D$ age: $22 \pm 3$ years; stature: $184 \pm 3 \mathrm{~cm}$; body mass: $85.7 \pm 3.2 \mathrm{~kg}$; and $\dot{V}_{\mathrm{O}_{2}} \max$ : $55.6 \pm 3.6 \mathrm{ml} \cdot \mathrm{kg}^{-1} \cdot \mathrm{min}^{-1}$. All subjects were professional players who played in the elite national competition, and testing was conducted during the preseason competition period. All players trained at least 8 times per week, including conditioning, skills, and strength training sessions. All subjects were informed of the experimental risks and signed an informed consent document before the investigation. The investigation was approved by an institutional review board for use of human subjects.

\section{Procedures}

Match Running Performance. During the games, each player wore the same portable global positioning satellite (GPS) unit fitted across his shoulder in a custom-made harness (SPI Elite and SPI 10, GPSports Systems, Australia) to record distance and velocity every second $(1 \mathrm{~Hz})$. After each match, the data were downloaded to a portable computer and analyzed using specialized software (GPSports Analysis and Team AMS, GPSports Systems, Australia). This device's technical error of measurement for measuring distance has previously been reported to be $5.5 \%(5)$.

Before analysis, the GPS data for each player were visually inspected for erroneous data. Any erroneous data were removed using the specialized GPS analysis software. The

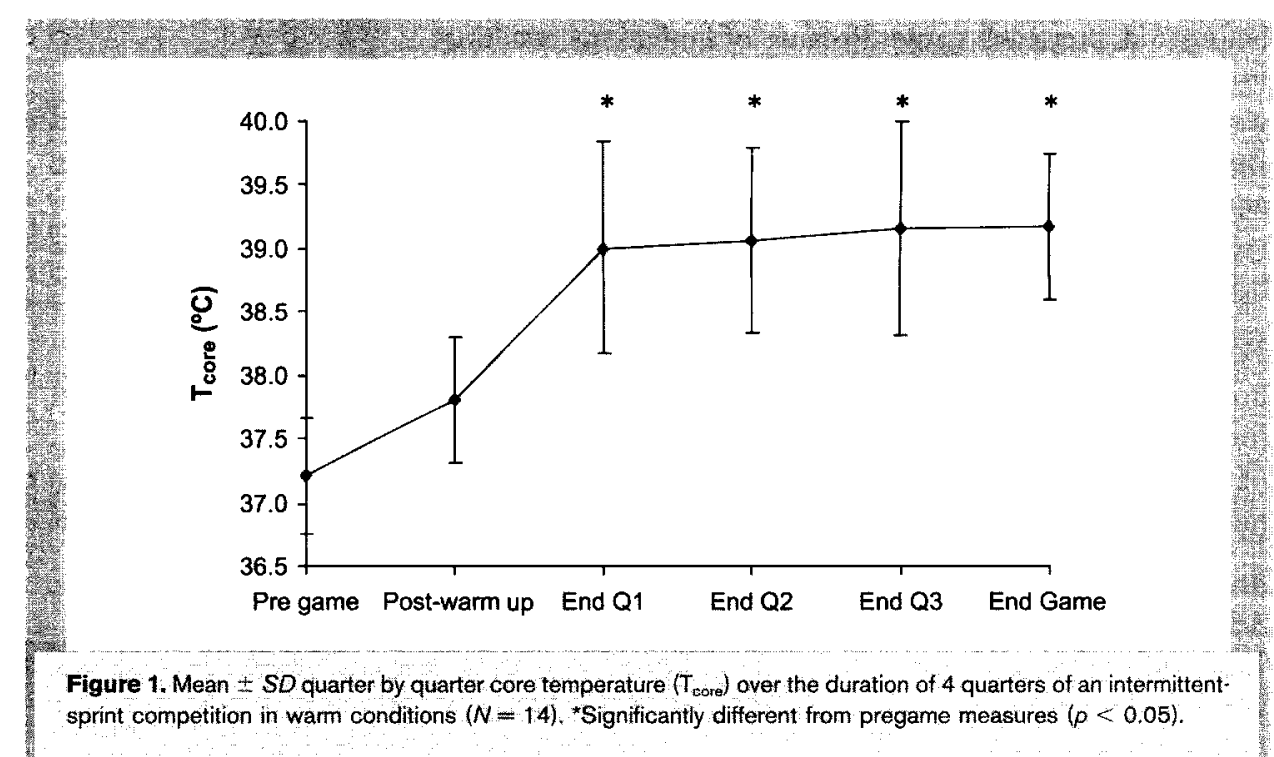

VOLUME 23 | NUMBER 4 | JULY 2009 
GPS data for distance traveled and the mean velocities collected during each quarter and the total game were then divided into 4 predefined categories (22):

low-intensity activity (LIA; speeds $<7.0 \mathrm{~km} \cdot \mathrm{h}^{-1}$ ); moderate-intensity activity (MIA; speeds of 7.0-14.4 $\mathrm{km} \cdot \mathrm{h}^{-1}$ ); high-intensity running (HIR; speeds $>14.5 \mathrm{~km} \cdot \mathrm{h}^{-1}$ ); and very-high-intensity running (VHIR; speeds $>20 \mathrm{~km} \cdot \mathrm{h}^{-1}$ ).

Repeated Countermovement Jump. Before and 10 minutes after each game, players performed 10 continuous maximal vertical jumps on a vertical jump mat (Jump, Axon, Portugal) to determine changes in voluntary recruitment of lower-body power. Repeated vertical jump efforts were required to be performed with no contribution from the upper body and in a countermovement motion to a squat depth of approximately $45^{\circ}$.

Core and Environmental Temperature. Each player's $\mathrm{T}_{\text {core }}$ was recorded on a handheld monitor with measures received from an ingestible telemetric capsule (VitalSense, Mini Mitter). This capsule was swallowed 5 hours before game commencement to ensure that it had passed into the gastrointestinal tract and would be insensitive to temperature changes resulting from food or fluid intake. The $T_{\text {core }}$ measures were recorded before game commencement and at the end of each 25-minute quarter, or when players left the field of play because of interchange rotation. Environmental WBGT and humidity were recorded during each quarter of the game (Questtemp ${ }^{\circ} 15$, Quest).

Blood Lactate, Body Mass, and Urine Specific Gravity. A 2- $\mu \mathrm{L}$ capillary sample of whole blood was sampled for measurement of $\left[\mathrm{La}^{-}\right]$(Lactate Scout, SensLab Gmb, Lepzig, Germany) at each quarter time break (or close to the break if players were interchanged). To estimate changes in body mass attributable to sweat loss, mass in minimal clothing (underwear) was measured on a set of calibrated scales (Model UC-321, A\&D Co. Ltd, Australia) immediately before and after each game. Because of.limitations resulting from collecting field-based competition data, individual fluid consumption was not accounted for in the change in mass. Before warm-up, each player provided a urine sample for analysis of USG to determine pregame hydration status by visual observation through a refractometer (URC-Ne, Vitech Scientific Ltd, West Śussex, UK).

Perceptual Measures. At least 15 minutes after game completion, players were asked to provide a session- RPE rating for the game and thermal comfort via 10-point (nothing to maximal) and 8-point (very very cold to very very hot) Likert rating scales, respectively.

\section{Statistical Analyses}

All data are reported as mean $\pm S D$. Associations between $\mathrm{T}_{\text {core }}$ and GPS parameters were determined by way of a Pearson correlation coefficient, and comparisons between pre- and postgame and within-game measures were

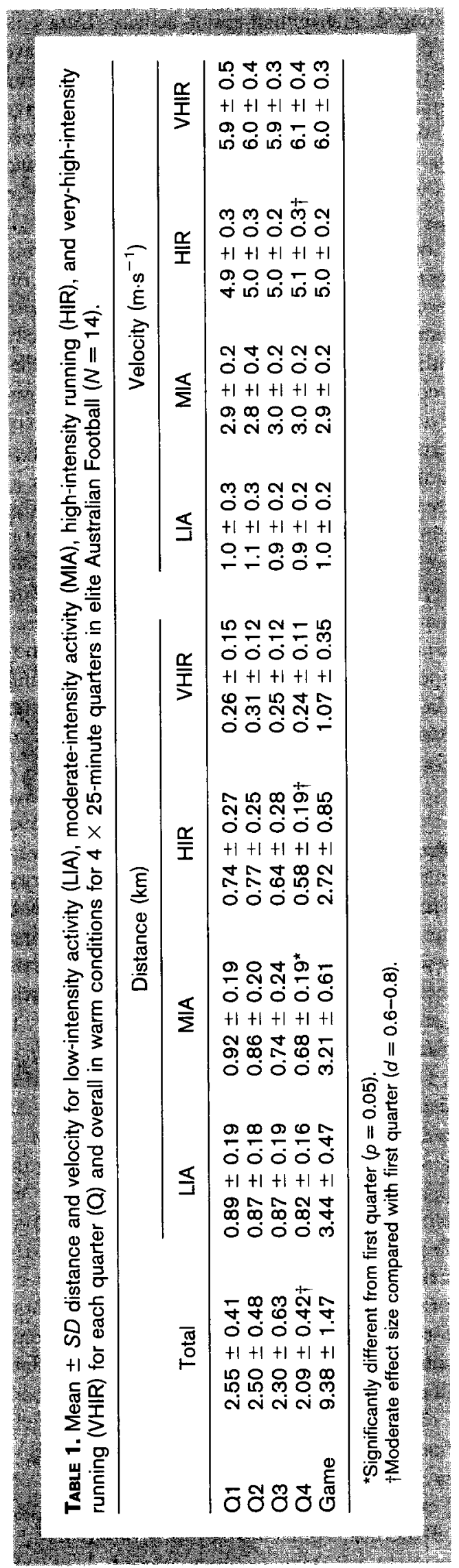

1240 Journal of Strength and Conditioning Research 


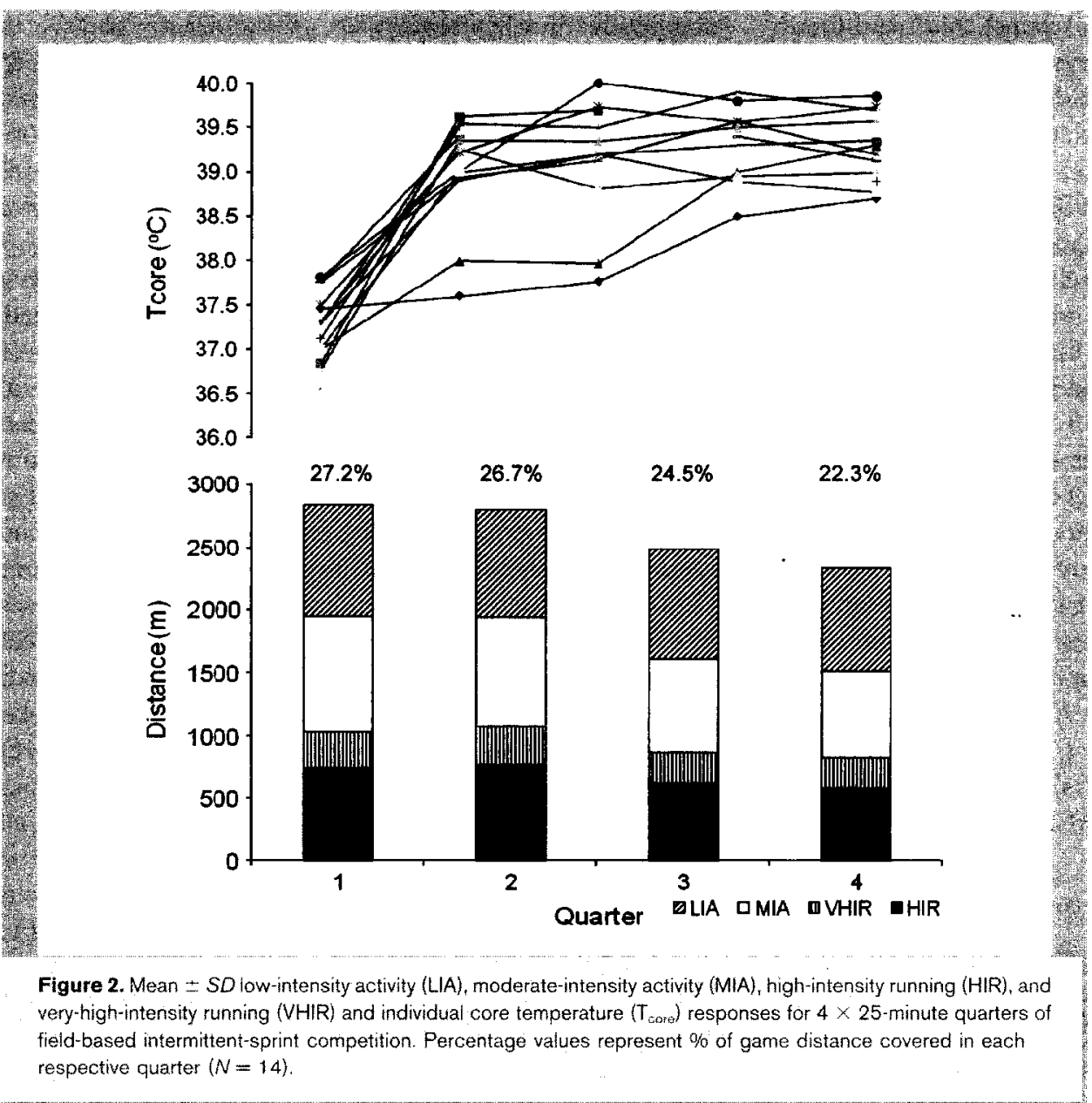

parameters, with an $\mathrm{ES}<0.2$ classified as trivial, $0.2-0.4$ as small, $0.4-0.7$ as moderate, and $>0.8$ as large.

\section{Results}

The response of $\mathrm{T}_{\text {core }}$ during the ARF game is presented in Figure 1. Peak $\mathrm{T}_{\text {core }}$ values were typically observed in the final quarter of the game, resulting in an overall rise of $2.11 \pm 0.73^{\circ} \mathrm{C}$. The majority $(86 \%)$ of the rise in $\mathrm{T}_{\text {core }}$ during the match $\left(1.81 \pm 0.99^{\circ} \mathrm{C}\right)$ occurred by quarter time. The GPS data for distance covered and mean velocity for each speed category (LIA, MIA, HIR, and VHIR) for each quarter are presented in Table 1.

Figure 2 shows total distance covered, percentage of total distance covered for each quarter, relative time spent in each speed zone, and individual player $T_{\text {core }}$ responses for each quarter. Players covered a total distance of $9.38 \pm 1.47 \mathrm{~km}$, of which $71 \%$ was spent completing LIA and MIA $(<14$ $\mathrm{km} \cdot \mathrm{h}^{-1}$ ), with the remainder

performed by way of a 1-way analysis of variance with significance set a priori at $p \leq 0.05$. Finally, effect size (ES) data were calculated (Cohen $d$ ) to determine the magnitude of effect of game duration on performance and $T_{\text {core }}$

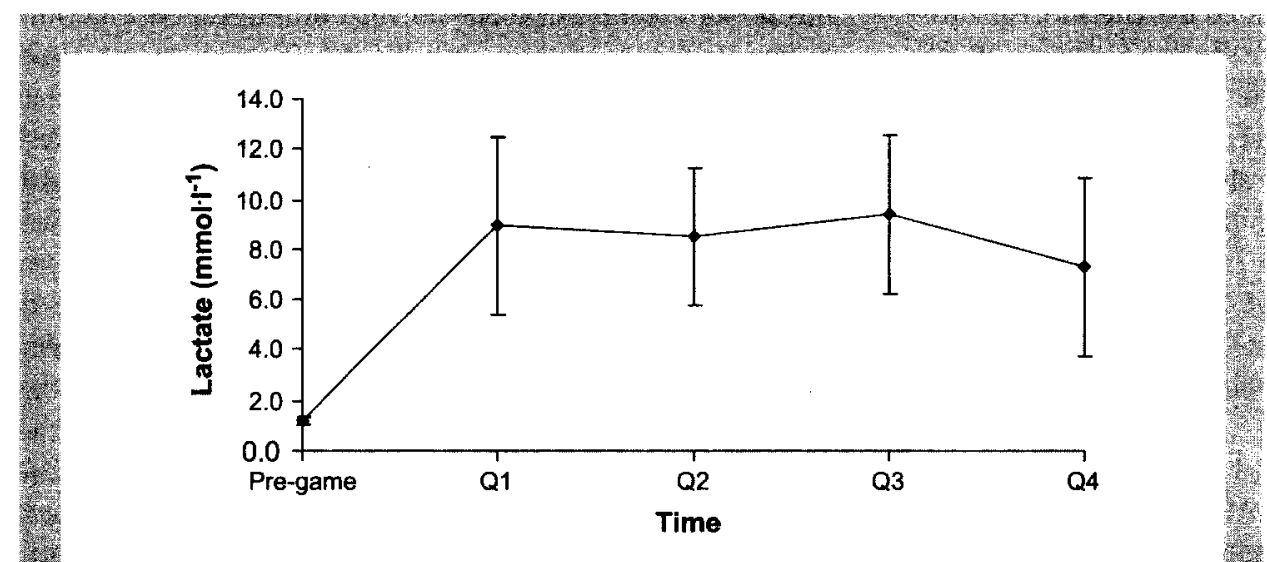

Figure 3. Mean \pm SD quarter by quarter blood lactate concentration over the duration of an intermittent-sprint competition in warm conditions $(N=14)$. Significantly different from pregame measures $(\rho<0.05)$. of activity either HIR $(18 \%)$ or VHIR $(11 \%)$. The MIA distance covered was significantly reduced $(p=0.05)$ in the fourth quarter compared with the first quarter. There were no other significant differences $(p>0.05)$ between each of the 4 quarters for either the distance or velocity in any other respective motion category. However, ES analyses indicated a moderate ES for a reduction in MIA distance covered in the third quarter $(d=0.62)$, a moderate ES for a reduction in the total distance covered in the fourth quarter $(d=0.72)$, and a moderate ES for a reduction in HIR in the fourth quarter $(d=0.61)$. Finally, there were moderate ESs between the first and fourth quarters, with a faster mean HIR velocity $(d=0.61)$. Specifically, as evidenced in Figure 2 , the reductions in total 
distance covered from the first to second, third, and fourth quarters were 2,10 , and $18 \%$, respectively, whereas the reductions in total distance from the second to third and fourth quarters were 8 and $14 \%$, respectively.

Correlation analysis between $T_{\text {core }}$ and GPS data indicated significant correlations $(p<0.05)$ for the relationships between the first-quarter rise in $\mathrm{T}_{\text {core }}$ and HIR velocity $(r=$ $0.72)$, first-quarter $\mathrm{T}_{\text {core }}$ and MIA velocity $(r=0.68)$, secondquarter $\mathrm{T}_{\text {core }}$ and LIA velocity $(r=-0.90)$, second-quarter $\mathrm{T}_{\text {core }}$ and MIA velocity $(r=0.88)$, fourth-quarter rise in $\mathrm{T}_{\text {core }}$ and VHIR distance $(r=0.70)$, and fourth-quarter $\mathrm{T}_{\text {core }}$ and MIA velocity $(r=0.73)$.

The $\left[\mathrm{La}^{-}\right]$values sampled after each quarter reached a plateau after the first quarter at $8.6 \pm 0.4 \mathrm{mmol} \cdot \mathrm{L}^{-1}$ (Figure 3 ). Pregame USG was $1.009 \pm 0.004$, and body mass change was $2.13 \pm 0.86 \mathrm{~kg}$ or $2.5 \pm 1.0 \%$ body mass $(85.67 \pm 3.19$ vs. $83.54 \pm 3.55$ for pre- and postgame mass, respectively). Session-RPE data indicated that the games were rated as an $8.6 \pm 1.4$ (very very hard) out of a possible 10 , and thermal comfort was rated as a $7.0 \pm 0.6$ (very hot) out of a possible 8 . Finally, no significant differences $(p>0.05)$ were evident between pre-and postgame repeated vertical jump efforts for height jumped $(38.9 \pm 3.0$ vs. $39.6 \pm 3.3 \mathrm{~cm}$ for pre- and postgame, respectively).

\section{Discussion}

This study investigated the association between $T_{\text {core }}$ responses and exercise intensity during field-based team sport competition. The present results indicate that reductions in MIA were associated with the maintenance of $\mathrm{T}_{\text {core, }}$ generally below $39.5^{\circ} \mathrm{C}$. Further, although HIR distance covered decreased over the duration of the game, the mean velocities attained within HIR and VHIR zones were not reduced. Accordingly, it seems that during competitive, freepaced exercise in warm conditions, players may prevent the excessive rise in $T_{\text {core }}$ predominantly by a reduction in MIA, possibly so as to minimize disruptions to HIR to maintain game performance.

Previous studies that have examined the thermoregulatory responses to soccer match play have reported mean peak $T_{\text {core }}$ values below $39.5^{\circ} \mathrm{C}(6,15)$. In the warmer environmental conditions encountered in the present study, the mean peak $\mathrm{T}_{\text {core }}$ also remained below $39.5^{\circ} \mathrm{C}$, although it demonstrated a rise in $\mathrm{T}_{\text {core }}$ of more than $2^{\circ} \mathrm{C}$. Notably, however, some players in previous studies and in the present research did reach $\mathrm{T}_{\text {core }}$ values approaching $40.0^{\circ} \mathrm{C}$, which are known to place athletes at an increased risk of heat illness (however, no signs or symptoms of heat-related illness were evident in the present study).

Several factors may account for the moderate $T_{\text {core }}$ values recorded. First, the nature of an ARF match consisting of $4 \times 25$-minute quarters with unlimited player interchange results in prolonged (5-20 minutes) recovery periods that may allow sufficient respite from exercise and minimize excessive rises in $T_{\text {core. }}$ Second, the self-paced nature of competitive intermittent-sprint games allows players to continually adjust exercise intensities or pace themselves to minimize any excessive rise in $T_{\text {core }}$. Finally, the improved effectiveness of convective cooling in an external environment compared with a laboratory, in addition to evaporative cooling mechanisms, may provide further protection against a critically high $\mathrm{T}_{\text {core }}(24)$.

The relationship of $T_{\text {core }}$ with constant-load exercise performance within laboratory settings is well established, and it has been shown that both a high $\mathrm{T}_{\text {core }}$ and faster rises in $\mathrm{T}_{\text {core }}$ are associated with a reduction in intensity or cessation of exercise $(8,23)$. Although the relationship of $T_{\text {core }}$ and intermittent-sprint activity in laboratory conditions have not been examined as widely, previous studies have shown that high ambient temperatures are associated with higher and faster $\mathrm{T}_{\text {core }}$ responses and reduced exercise performance $(16,18)$. The current study attempted to extend this work into a more ecologically valid competition environment by examining the relationship of $\mathrm{T}_{\text {core }}$ and (free-paced) intermittent-sprint exercise performance in an elite, competitive (ARF) match. Similar to the data of Morris et al. (18) from intermittent-sprint exercise under controlled laboratory conditions, the current study indicates that there was an association between higher work intensities and a larger rise in $T_{\text {core }}$ in the first (25-minute) quarter of a game. Previous investigators have reported larger and faster increments in $\mathrm{T}_{\text {core }}$ to be an important factor involved in performance reduction $(8,11,19)$. In the present study, a reduction in total and MIA distance was evident as the game continued, along with small reductions in HIR distance. Additionally, mean HIR velocity showed a small increase in the final quarter compared with the first. The relationship between MIA and $T_{\text {core }}$ suggests that a greater increase in $T_{\text {core }}$ may result in the reduction of MIA during later stages of the game. The pattern of a plateau in $T_{\text {core }}$ after the first quarter, in association with a reduction in MIA and HIR distance while maintaining VHIR activity, may indicate the use of pacing strategies to ensure control of $T_{\text {core }}$ within tolerable limits.

Although the exact mechanisms limiting exercise performance associated with a critically high $T_{\text {core }}$ or an increased rate of $T_{\text {core }}$ are not yet fully understood (23), the classical models of thermoregulation suggest that there are critical temperatures that result in overloading the cardiovascular and metabolic systems (1). More recently, however, reductions in CNS drive and down-regulation of neural recruitment and muscle activation have been proposed as more likely mechanisms $(12,19)$. On the basis of the present results, it is difficult to suggest the exact mechanisms underlying the progressive decrements in physical performance in the respective velocity zones as the game progressed. A range of factors such as glycogen depletion, hypohydration, hyperthermia, accumulation of potassium in muscle interstitium, and increased perception of effort may be associated with reductions in work during prolonged, intermittentsprint sports $(2,10)$. Nonetheless, an important finding of this 
study is that the rise in $T_{\text {core }}$ was associated with a decline in the distances covered-in particular, a reduction in MIA-while HIR and VHIR velocities (and postgame VJ efforts) were maintained. This may suggest that as VHIR is critical for game performance, to control the rise in internal thermal load, there is a selective reduction in noncritical work (jogging and below-threshold running), as observed in the reduction in MIA.

A discussion of performance decrement in team sport exercise should entail a multifactorial approach, and, as such, there are a variety of other factors to consider. In this study, moderate to high blood $\left[\mathrm{La}^{-}\right]$concentrations, as an indicator of the extent of anaerobic glycolysis and possible anaerobic metabolic perturbations, were observed throughout the ARF matches, similar to levels previously reported in other team sports that demand prolonged, intermittent sprinting such as soccer (2) and rugby league (3). These results, combined with GPS data showing that players completed $11.3 \pm 3.5 \%$ of total match distance through VHIR, suggest that there is a high glycolytic demand in ARF. Indeed, the $\left[\mathrm{La}^{-}\right]$values found in this study most likely reflect the balanced response to many high-intensity efforts during the game and indicate that the rate of glycolysis is high for periods during a game. In agreement with previous studies that have not observed a relationship between metabolic markers of fatigue and reductions in intermittent-sprint exercise in hot, controlled environments $(4,26)$ and during soccer match play $(10)$, we also did not observe a relationship between $\left[\mathrm{La}^{-}\right]$and intermittent-sprint performance.

Hypohydration has been suggested to be a contributor to performance reductions during both continuous and intermittent-sprint exercise $(7,13)$. In this study, we observed a $2.13 \pm$ $0.86 \mathrm{~kg}(2.5 \%)$ decrement in body mass after the 100 minutes of match play. Further, all players were similarly hyperhydrated before game commencement, as evidenced by the low pregame urine USG values, because of standardized fluid ingestion protocols. Although previous studies have shown performance reductions in intermittent-sprint performance in laboratory studies with $2.0 \pm 0.7 \%$ body mass loss, we did not observe reductions in VHIR or repeated VJ performance in this study. Based on previous research, it is likely that the extent of dehydration was not sufficient to blunt peak power in a single set of repeated VJ efforts (9). Therefore, in the absence of explicit markers associated with in-competition performance reduction (or reduced work performed), similar results from laboratory conditions for intermittent-sprint and continuous exercise have previously indicated that sufficient increases in $\mathrm{T}_{\text {core }}$ result in down-regulation of central activation of muscle recruitment $(12,27)$. As such, it may be that the reduction in both mean velocity and distance covered in the fourth quarter, particularly in MIA, was a result of $T_{\text {core }}$ reaching sufficiently high temperatures for a reduction in muscle recruitment (4). As VHIR is integral to game performance, and as both games involved highly competitive fourth quarters, the selective reduction in MIA while maintaining VHIR may have been a result of this proposed reduction in activity to control the internal thermal environment. Given the context of in-game data collection, it must be noted that changes in the game environment and player interchanges may also result in a reduced requirement of physical activity in the closing periods of a game regardless of $\mathrm{T}_{\text {core }}$ (although both games in which the current data were collected involved physically demanding final quarters).

In conclusion, this is the first study to report the association of changes in game activity patterns and $T_{\text {core }}$ in warm conditions during free-paced, elite team sport competition. Unlike laboratory data, the free-paced nature of the game allows regulation of exercise intensity to ensure a plateau in $\mathrm{T}_{\text {core, }}$ and, accordingly, $\mathrm{T}_{\text {core }}$ rarely increased above $39.5^{\circ} \mathrm{C}$. Additionally, this regulation of exercise intensity seems to be at the expense of MIA rather than HIR or VHIR, as is reported in laboratory data. Although factors related to the cellular metabolic environment and hydration status are also likely to contribute, the association between MIA and $\mathrm{T}_{\text {core, }}$ while maintaining VHIR and, to a lesser extent, HIR, may suggest the use of pacing strategies to control the rise in the internal heat load while continuing to engage in regular, intense efforts during team sport exercise in warm conditions.

\section{Practical Applications}

Intermittent-sprint exercise in the heat, as performed by many team sports during summer competition or preseason training, can result in increased internal body temperature. The present research highlights that athletes may adopt pacing strategies to limit the continued rise in core body temperature based on a reduction of work during nonessential activities. As the demands of competition dictate continued engagement in high-intensity exercise, reductions in the volume and intensity of low-intensity activity are more evident than those of high-intensity activity, which is further associated with the prevention of $T_{\text {core }}$ rising excessively. Accordingly, coaches and practitioners may adjust expected game demands in the heat or, alternatively, attempt to counter these adopted pacing strategies to maintain or increase the workload performed, particularly toward the end of a match.

\section{ACKNOWLEDGMENTS}

This study was funded by a CSU Faculty of Education Research Grant. The authors would like to thank Joel Hocking for his valuable assistance with the data collection. Also, the authors would like to thank the staff and players at the Essendon Football Club for their assistance.

\section{ReFerences}

1. Adams, WC, Fox, RH, and Fry, AJ. Thermoregulation during marathon running in cool, moderate, and hot environments. $J A p p l$ Physiol 38: 1030-1037, 1975.

2. Bangsbo, J, Iaia, FM, and Krustrup, P. Metabolic response and fatigue in soccer. Int J Sports Physiol Perform 2: 111-127, 2007. 
3. Coutts, AJ, Reaburn, PRJ, and Abt, GA. Heart rate, blood lactate concentrations, and estimated energy expenditure in a semi-professional rugby league team during match play: a case study. $J$ Sports Sci 21: 97-103, 2003.

4. Drust, B, Rasmussen, P, Mohr, M, Nielsen, B, and Nybo, L. Elevations in core and muscle temperature impairs repeated sprint performance. Acta Physiol Scand 183: 181-190, 2005.

5. Edgecomb, SJ and Norton, KI. Comparison of global positioning and computer based tracking systems for measuring player movement distance during Australian football. J Sci Med Sport 9: 25-32, 2006.

6. Edwards, A and Clark, NA. Thermoregulatory observations in soccer match play: professional and recreational level applications using an intestinal pill system to measure core temperature. $\mathrm{Br} J$ Sports Med 40: 133-138, 2006.

7. Gonzalez-Alonso, J, Calbert, JA, and Nielsen, B. Metabolic and thermodynamic responses to dehydration-induced reductions in muscle blood flow in exercising humans. $J$ Physiol (London) 520 : 577-589, 1999.

8. Gonzalez-Alonso, J, Teller, C, Anderson, SL, Jensen, FB, Hyldig, T, and Nielsen, B. Influence of body temperature on the development of fatigue during prolonged exercise in the heat. J Appl Physiol 86: 1032-1038, 1999.

9. Judelson, C, Maresh, M, Farrell, MJ, Yamamoto, LM, Armstrong, LE, Kraemer, WJ, Volek, JS, Spiering, BA, Casa, DJ, and Anderson, JM. Effect of hydration state on strength, power, and resistance exercise performance. Med Sci Sports Exerc 39: 1817-1824, 2007.

10. Krustrup, P, Mohr, M, Steensberg, A, Bencke, J, Kjaer, M, and Bangsbo, J. Muscle and blood metabolites during a soccer game: implications for sprint performance. Med Sci Sports Exerc 38: 11651174,2006

11. Macdougall, JD, Reddan, WG, Layton, CR, and Dempsey, JA. Effects of metabolic hyperthermia on performance during heavy prolonged exercise. J Appl Physiol 36: 538-544, 1974.

12. Marino, FE. Anticipatory regulation and avoidance of catastrophe during exercise-induced hyperthermia. Comp Biachem Physiol B Biochem Mol Biol 139: 561-569, 2004.

13. Maxwell, N, Gardner, F, and Nimmo, M. Intermittent running: muscle metabolism in the heat and effect of hypohydration. Med Sci Sports Exerc 31: 675-683, 1999.

14. Meir, R, Brooks, L, and Shield, T. Body weight and tympanic temperature change in professional rugby league players during night and day games: a study in the field. $J$ Strength Cond Res 17: $566-572,2003$.
15. Mohr, M, Krustrup, P, Nybo, L, Nielsen, JJ, and Bangsbo, J. Muscle temperature and sprint performance during soccer matchesbeneficial effect of re-warm up at half time. Scand J Med Sci Sports 14: 156-162, 2004.

16. Mohr, M, Rasmussen, P, Drust, B, Nielsen, B, and Nybo, L. Environmental heat stress, hyperammonemia and nucleotide metabolism during intermittent exercise. Eur J Appl Physiol 97: 89-95, 2006.

17. Morris, JG, Nevill, ME, Boobis, LH, Macdonald, IA, and Williams, C. Muscle metabolism, temperature and function during prolonged, intermittent, high-intensity running in air temperatures of $33^{\circ}$ and $17^{\circ} \mathrm{C}$. Int J Sports Med 26: 805-814, 2005.

18. Morris, JG, Nevill, ME, and Williams, C. Physiological and metabolic responses of female games and endurance athletes to prolonged, intermittent, high-intensity running at $30^{\circ}$ and $16^{\circ} \mathrm{C}$ ambient temperatures. Eur J Appl Physiol 81: 84-92, 2000.

19. Morrisson, S, Sleivert, GC, and Cheung, SS. Passive hyperthermia reduces voluntary activation and isometric force production. Eur $J$ Appl Physiol 91: 729-736, 2004.

20. Nielsen, B, Hales, JRS, Strange, S, Christensen, NJ, Warberg, J, and Saltin, B. Human circulatory and thermoregulatory adaptations to heat acclimation during exercise in a hot, dry environment. J Physiol (London) 460: 467-485, 1993.

21. Nybo, $L$ and Nielsen, B. Hyperthermia and central fatigue during prolonged exercise in humans. J Appl Physiol 91: 1055-1060, 2001.

22. Rampinini, E, Coutts, AJ, Castagna, C, Sassi, R, and Impellizzeri, F. Variation in top level soccer match performance. Int I Sports Med 28: 1018-1024, 2007.

23. Reilly, T, Drust, B, and Gregson, W. Thermoregulation in elite athletes. Curr Opin Clin Nutr Metab Care 9: 666-671, 2006.

24. Saunders, AG, Dugas, JP, Tucker, R, Lambert, MI, and Noakes, TD. The effects of different air velocities on heat storage and body temperature in humans cycling in a hot, humid environment. Acta Physiol Scand 183: 241-255, 2005.

25. St Clair Gibson, A, Lambert, EV, Rauch, LH, Tucker, R, Baden, DA, Foster, $\mathrm{C}$, and Noakes, TD. The role of information processing between the brain and peripheral physiological systems in pacing and perception of effort. Sports Med 36: 705-722, 2006.

26. Sunderland, $\mathrm{C}$ and Nevill, ME. High-intensity intermittent running and field hockey skill performance in the heat. $J$ Sports Sci 23: 531$540,2005$.

27. Tucker, R, Rauch, L, Harley, YX, and Noakes, TD. Impaired exercise performance in the heat is associated with an anticipatory reduction in skeletal muscle recruitment. Plugers Arch 448: 422-430, 2004. 


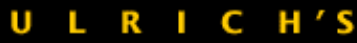
Periodicals Directory"

The globalsourcefor
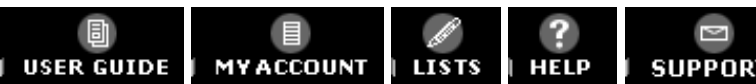

SUPPORT

\section{J ournal of Strength and Conditioning Research}

$\triangle$ BACK TO RESULTS

SEARCH MY LI BRARY'S CATALOG: ISSN Search | Title Search

\begin{tabular}{|c|c|c|c|c|c|c|}
\hline $\begin{array}{c}\text { Basic } \\
\text { Description }\end{array}$ & \multicolumn{2}{|c|}{$\begin{array}{l}\text { Other Editions/ } \\
\text { Formats }\end{array}$} & $\begin{array}{c}\text { Abstracting/ } \\
\text { Indexing \& Article } \\
\text { Access }\end{array}$ & $\begin{array}{l}\text { Publisher \& } \\
\text { Ordering } \\
\text { Information }\end{array}$ & $\begin{array}{c}\text { Advertising, Rights, } \\
\text { Demographics }\end{array}$ & Reviews \\
\hline \multicolumn{7}{|c|}{ 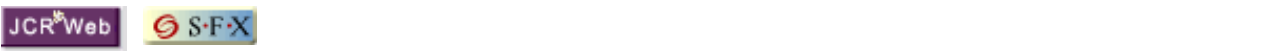 } \\
\hline \multicolumn{7}{|c|}{ Click highlighted text for a new search on that item. } \\
\hline \multicolumn{2}{|c|}{ Table of Contents: } & \multicolumn{3}{|c|}{ Click here to view } & & \\
\hline \multicolumn{2}{|c|}{ ISSN: } & \multicolumn{3}{|c|}{$\overline{1064-8011}$} & & \\
\hline \multicolumn{2}{|l|}{ Title: } & \multicolumn{3}{|c|}{$\begin{array}{l}\text { J ournal of Strength and Conditioning } \\
\text { Research }\end{array}$} & $\nabla \underline{\text { Additio }}$ & al Title Information \\
\hline \multicolumn{2}{|c|}{ Publishing Body: } & \multicolumn{5}{|c|}{ National Strength and Conditioning Association } \\
\hline \multicolumn{2}{|c|}{ Country: } & \multicolumn{3}{|c|}{ United States } & & \\
\hline \multicolumn{2}{|l|}{ Status: } & \multicolumn{3}{|c|}{ Active } & & \\
\hline \multicolumn{2}{|l|}{ Start Year: } & \multicolumn{3}{|c|}{1987} & & \\
\hline \multicolumn{2}{|l|}{ Frequency: } & \multicolumn{3}{|c|}{ Quarterly } & & \\
\hline \multicolumn{2}{|c|}{ Volume Ends: } & \multicolumn{3}{|c|}{ Dec } & & \\
\hline \multicolumn{2}{|c|}{ Document Type: } & \multicolumn{3}{|c|}{ J ournal; Academic/Scholarly } & & \\
\hline \multicolumn{2}{|c|}{ Refereed: } & \multicolumn{3}{|c|}{ Yes } & & \\
\hline \multicolumn{2}{|c|}{ Abstracted/ I ndexed: } & \multicolumn{3}{|l|}{ Yes } & & \\
\hline \multicolumn{2}{|c|}{ Media: } & \multicolumn{3}{|c|}{ Print } & & \\
\hline \multicolumn{2}{|c|}{$\begin{array}{l}\text { Alternate Edition } \\
\text { ISSN: }\end{array}$} & 1533 & -4287 & & & \\
\hline Size: & & Stan & dard & & & \\
\hline Language: & & Text & in English & & & \\
\hline Price: & & $\begin{array}{l}\text { USD } \\
\text { USD } \\
\text { (effe }\end{array}$ & $\begin{array}{l}416 \text { subscription } \\
448 \text { subscription } \\
\text { ctive } 2009 \text { ) }\end{array}$ & $\begin{array}{l}r \text { year domes } \\
r \text { year foreigr }\end{array}$ & $\begin{array}{l}\text { tic to institutions } \\
\text { to institutions }\end{array}$ & \\
\hline Subject: & & $\frac{\text { MED }}{\mathrm{PHYS}}$ & $\begin{array}{l}\text { CAL SCIENCES - } \\
\text { ICAL FITNESS A }\end{array}$ & $\begin{array}{l}\text { ORTS MEDIC } \\
\text { HYGIENE }\end{array}$ & & \\
\hline Dewey \#: & & 617. & & & & \\
\hline LC\#: & & GV7 & & & & \\
\hline Circulation & & 2752 & 7 paid and contr & & & \\
\hline Special Fea & res: & Inclu & des Advertising, & arts, Illustrati & ons & \\
\hline Article I nd & & Inde & x Available & & & \\
\hline Pages per I & ue: & 120 & & & & \\
\hline Compositic & & Offs & & & & \\
\hline Editor(s): & & Willi & m J Kraemer, Hi & n Lucke (Man & aging Editor) & \\
\hline URL: & & http: & //www.nsca-lift.c & Publications/ & $\#$ \#SCR & \\
\hline Descriptior & & $\begin{array}{l}\text { Publ } \\
\text { spor }\end{array}$ & $\begin{array}{l}\text { shes original rese } \\
s \text { and exercise. }\end{array}$ & ch dealing wi & th strength and & nditioning in \\
\hline
\end{tabular}

\section{ADDI TI ONAL TITLE I NFORMATI ON}

\section{Alternate Title: Medline Abbreviated title: J Strength Cond Res \\ Title History: $\quad$ Formerly (until 1993): The J ournal of Applied Sport Science Research (1557-6345)}

त Back to Top Add this item to: (select a list)

\section{Request this title:}

I'd like to request this title.

Corrections:

Submit corrections to Ulrich's about this title.

If yes, click GO! to contact Ulrich's about updating your title listings in the Ulrich's database.
- Print • Download $\cdot \underline{\text { E-mail }}$ 